\title{
Specific Mechanical Energy and Thermal Degradation of Poly(lactic acid) and Poly(caprolactone)/Date Pits Composites
}

\author{
A. A. Mohamed (iD, S. Hussain, M. S. Alamri, M. A. Ibraheem, and Akram A. Abdo Qasem \\ Department of Food Science, King Saud University, Riyadh, Saudi Arabia \\ Correspondence should be addressed to A. A. Mohamed; abdmohamed@ksu.edu.sa
}

Received 15 January 2018; Accepted 28 February 2018; Published 12 April 2018

Academic Editor: Hossein Roghani-Mamaqani

Copyright (C) 2018 A. A. Mohamed et al. This is an open access article distributed under the Creative Commons Attribution License, which permits unrestricted use, distribution, and reproduction in any medium, provided the original work is properly cited.

\begin{abstract}
The compatibility of date pits (DP) with polylactic acid (PLA) or polycaprolactone (PCL) is investigated. Composites were prepared by compounding PLA or PCL with date pits at 10, 20,30, and $40 \% \mathrm{wt} / \mathrm{wt}$ and extruded. Wheat vital gluten (VG) was also used as a filler and in combination with DP. The specific mechanical energy (SME) was calculated and the composites thermal properties were tested using DSC (peak temperature, enthalpic relaxation, and glass transition) and TGA (degradation temperature and mechanism and degradation kinetics). Because DP is hard filler, the SME of PCL-DP composites increased as the amount of filler increased. At $40 \%$ fill, the SME decreased due to the lubricating effect of oil found naturally in DP. As illustrated by lower SME, PLA composites exhibited softer texture because PLA is harder than DP. The DSC melting peak temperature of both polymers has increased at higher DP; however, PLA exhibited enthalpic relation between 66 and $68^{\circ} \mathrm{C}$. The TGA profile of the composites displayed two distinct peaks versus one peak for the pure polymer. The degradation kinetics showed multistep process for the composites and one-step process for the pure polymer. The utilization of date pits as a hard filler in developing biodegradable plastics is good for the environment and a value added for the date industry.
\end{abstract}

\section{Introduction}

Despite the convenience and practicality of the petroleumbased polymers used for food and other consumer goods packing, there is evidence of ecological disturbance. There is an ongoing appeal and need for developing new uses for agricultural coproducts for environmental protection, such as introducing biodegradable plastics. The development and use of biodegradable plastics in packaging for environmental protection has been stimulated by the public's concerns and interest, especially in food packaging, the biggest users of packaging material.

Date pits (DP), which is $25 \%$ of the date fruit, have been an environmental problem for the date industry in the United States and other countries; however, it is used as animal feed in the Middle East [1, 2]. Hamada et al. (2002) [3] reported that the composition of date pits includes $12 \%$ fat, $6 \%$ protein, $1.5 \%$ ash, and $67 \%$ carbohydrates [4]. The reported mentioned no glass transition as measured with Modulated Differential Scanning Calorimetry (MDSC), indicating high crystallinity as well as the ability of the
DP to hold $29 \%$ unfreezable water. DP fiber is composed of neutral detergent fiber 75\%, acid detergent fiber 57.5\% (neutral less hemicellulose), hemicellulose 17.5\%, lignin 11\%, cellulose $42.5 \%$, and ash $4 \%$. In the presence of DP, the mechanical properties, that is, tensile strength (TS) and Izod impact strength (IIS) of polyethylene, were reduced [5] and $\mathrm{Tg}$ of polystyrene and the heat of fusion of HDPE dropped as well.

PLA thermal degradation is caused by random mainchain scission reaction, as well as depolymerization, oxidative degradation, and trans-esterification reactions. As different processing conditions were adopted in terms of temperature, moisture removal, and nitrogen atmosphere, reports indicated that intermolecular chain reactions took place under strong degradative conditions of polylactic acid (PLA) and polybutyrate (PBAT), produced PLA/PBAT copolymers with improved phase dispersion. Chemiluminescence kinetic analysis showed that PLA degradation is a multistep process [6-14].

Polycaprolactone (PCL) is biodegradable polyester used in agricultural composites preparation and biomedical 
devices [15-17], but its application has been limited because of the relatively high price, as well as some functional properties limitations. Nonetheless, blending PCL and other biodegradable polymers with renewable or synthetic materials have proven to be effective and economical [18]. Recently, different biomaterials have been blended successfully with polyesters for producing completely biodegradable composites [2, 1921].

Some attempts were made to incorporate plant based proteins in different polymer composites $[22,23]$. The DSC and thermogravimetric analysis (TGA) data of polycaprolactone (PCL) and wheat gluten composite showed that obvious physical interaction between PCL and gluten was present. The FTIR analysis verified the physical nature of this interaction as opposed to chemical interaction [23, 24]. Solid state FTIR analysis of polylactic acid (PLA) and gluten composites showed that amide I and II peaks significantly decreased, signifying gluten heat-degradation, while a strong peak, corresponding to ester formation between PLA and hydrolyzed gluten molecules, appeared at $1750 \mathrm{~cm}^{-1}$ [23]. By now, it is clear the advantages of adding nanomaterial (nanoclays or carbon nanotubes) in comparison to both of their conventional filler counterparts and base polymer. Compared to microparticle additives, nanoparticles confer significant property improvements at very low loading. At less than 5\% nanoparticles load, polyamide and polymethyl methacrylate showed significant improvement in their mechanical properties $[25,26]$.

Characterization of amorphous polymers and semiamorphous includes determining glass transition, melting temperature, enthalpic relaxation, conductivity and mechanical properties, and heat capacity, or any other physical properties are enormously different from those of crystalline materials. Additionally, the physical properties of amorphous materials can change with time as the polymer relaxes (enthalpic relaxation) toward an equilibrium state during aging, which can complicate their analysis. The process of enthalpic relaxation (physical aging) is associated with a decrease in the energy content of the material [27]. Physical aging is a very important process for the analytical and technological state of amorphous polymers. Differential scanning calorimetry (DSC) can quantify the energy (heat) content of a polymer; therefore, differences in the physical properties of the anticipated end-use can be predicted. At a temperature below glass transition $(\mathrm{Tg})$, amorphous structures have very low molecular mobility and are not at equilibrium $[28,29]$. Since the energy close to $\mathrm{Tg}$ is higher than it should be at equilibrium, the energy of the material will gradually decrease as it ages toward equilibrium. Once the material is heated above $\mathrm{Tg}$, it has high molecular mobility and is in thermal equilibrium. Enthalpic recovery is the recovery of the energy that the polymer gave up (dissipated) as it relaxed toward an equilibrium state over time [30]. Enthalpic recovery, as detected by DSC, is an endothermic peak located beneath the $\mathrm{Tg}$ profile of aged amorphous polymers.

The two polymers selected for this work are PLA which is biodegradable biopolymer and produced from agriculture coproducts, but it is costly and hard, and PCL a synthetic polymer with very low melting temperature as well as high cost. These characteristics (cost, hardness, and low melting point) could limit their utilization. Date pits are considered environmental hazard in the date industry. The objective of this research was to evaluate date pits utilization as lowcost hard filler for PLA and PCL to produce green polymer composites with mechanical properties suitable for light weight construction materials or other applications. The effect of DP on specific mechanical energy of PLA and PCL during extrusion will be determined. The thermal properties and degradation kinetics of the composites will be evaluated.

\section{Materials and Methods}

2.1. Materials. PLA and PCL were purchased from Sigma Aldrich (St. Louis, MO). Date pits sample, a by- product of date processing industry, was donated by a local date packing company.

2.2. Composites Preparation. Date pits soaked in water for three days at $4^{\circ} \mathrm{C}$ and then wet-milled and oven dried at $90^{\circ} \mathrm{C}$. The moisture content was measured according to AACCI standard method 44-18A and recorded as $8 \%$ moisture content. The powdered material was dry mixed at different levels with PLA or PCL as shown in Table 1. Composite blends were extruded using a Leistritz corotating twin-screw extruder (American Leistritz Extruder, Branchburg, NJ) with an L/D ratio of $30: 1$. The screw was designed for complete mixing of $\mathrm{DP} /$ polymer composites while limiting thermal degradation of the bio-based components using the configuration is listed in Table 2. For conveying elements, the pitch and length $(\mathrm{mm})$ are given, and, for kneading blocks (KB), the angle $\left(^{\circ}\right)$ between blocks and length $(\mathrm{mm})$ is given. The barrel had 7 different temperature zones, each $90 \mathrm{~mm}$ long, which were set and maintained at $40^{\circ} \mathrm{C}$ (feed throat), $60^{\circ} \mathrm{C}$ (zones 2-6), and $60^{\circ} \mathrm{C}$ (die) for PCL composites. For PLA composites, the extruder temperatures were set at $40^{\circ} \mathrm{C}$ (feed throat), $75^{\circ} \mathrm{C}$ (Zone 2 ), $125^{\circ} \mathrm{C}$ (Zone 3 ), $175^{\circ} \mathrm{C}$ (zones $4-6$ ), and $180^{\circ} \mathrm{C}$ (die). The strand die was $6.0 \mathrm{~mm}$ in diameter. The screw speed was set at $100 \mathrm{rpm}$. Blends (powder) were fed manually after being thoroughly mixed. Specific mechanical energy (J.g) was calculated using the following:

$$
\mathrm{SME}=\frac{2 \pi \omega \mathrm{To}}{\dot{m}}
$$

where $\omega$ is the screw speed (rpm), To is the corrected torque $(\mathrm{N} \cdot \mathrm{m})$, and $\dot{m}$ is the output $(\mathrm{g} / \mathrm{min})$. Collected samples were milled using a cryogenic mill (SPEX 6870, Metuchen, NJ). Both PCL and PLA had moisture contents under 0.5\%, and the gluten and date pit moistures were around $6 \%$ dry weight basis.

2.3. Deferential Scanning Calorimetry. Samples were analyzed using TA Instrument Modulated DSCTM Q1000 equipped with refrigeration cooling system (TA Instruments Thermal Analysis and Rheology, New Castle, DE 19720). Samples $\left(50 \mathrm{mg}\right.$ ) were run at $10^{\circ} \mathrm{C} / \mathrm{min}$ ramp speed from 0 to $200^{\circ} \mathrm{C}$, isotherm for $1 \mathrm{~min}$, cooled at $10^{\circ} \mathrm{C} / \mathrm{min}$ back to $0^{\circ} \mathrm{C}$, and isotherm for $1 \mathrm{~min}$. The DSC was calibrated using indium 
TABLE 1: Component concentrations (\% dry basis) in blends prepared by Leistritz extruder.

\begin{tabular}{|c|c|c|c|c|}
\hline Blend & Polycaprolactone & Polylactic acid & Vital gluten & Date pits \\
\hline 1 & 100 & & & \\
\hline 2 & & 100 & & \\
\hline 3 & 60 & & 40 & \\
\hline 4 & & 60 & 40 & \\
\hline 5 & 90 & & & 10 \\
\hline 6 & 80 & & & 20 \\
\hline 7 & 70 & & & 30 \\
\hline 8 & 60 & & & 40 \\
\hline 9 & & 90 & & 10 \\
\hline 10 & & 80 & & 20 \\
\hline 11 & & 70 & & 30 \\
\hline 12 & & 60 & & 40 \\
\hline 13 & 60 & & 20 & 20 \\
\hline 14 & & 60 & 20 & 20 \\
\hline 15 & 75 & & 25 & \\
\hline 16 & 75 & & 25 & \\
\hline 17 & 75 & & & 25 \\
\hline 18 & 75 & & & 25 \\
\hline
\end{tabular}

TABLE 2: Screw configuration for Leistritz twin-screw extruder.

\begin{tabular}{lc}
\hline Screw elements & Description \\
\hline $15 / 90$ & Conveying \\
$15 / 30$ & Conveying \\
$15 / 30$ & Conveying \\
$15 / 30$ & Conveying \\
$7.5 / 30$ & Conveying \\
$7.5 / 30$ & Conveying \\
$30^{\circ} / 20 \mathrm{~KB}$ & Kneading block \\
$10 / 30$ & Conveying \\
$60^{\circ} / 20 \mathrm{~KB}$ & Kneading block \\
$60^{\circ} / 20 \mathrm{~KB}$ & Kneading block \\
$10 / 30$ & Conveying \\
$30^{\circ} / 20 \mathrm{~KB}$ & Kneading block \\
$60^{\circ} / 20 \mathrm{~KB}$ & Kneading block \\
$60^{\circ} / 20 \mathrm{~KB}$ & Kneading block \\
$10 / 30$ & Conveying \\
$60^{\circ} / 20 \mathrm{~KB}$ & Kneading block \\
$60^{\circ} / 20 \mathrm{~KB}$ & Kneading block \\
$30^{\circ} / 20 \mathrm{~KB}$ & Kneading block \\
$7.5 / 30$ & Conveying \\
End Cap & \\
\hline
\end{tabular}

standard. A nitrogen flow rate of $24 \mathrm{~cm}^{3} / \mathrm{min}$ was maintained during the run. The DSC parameters, such as $\Delta H$, onset, and peak were calculated using TA instrument software and the area under the curve was used as the $\Delta H$ value. Since PLA melting temperature $\left(180^{\circ} \mathrm{C}\right)$ is higher than both biomaterials (biofillers), it was used as the upper limit of heating.
2.4. Thermogravimetric Analysis. Thermogravimetric analysis (TGA) measurements were taken using a TGA 2050 (TA Instruments Thermal Analysis and Rheology, New Castle, DE 19720). PLA or PCL composites were powdered using a Brinkmann/Retsch high-speed shaker mill. Samples (5-10 mg) were heated from $30^{\circ} \mathrm{C}$ to $800^{\circ} \mathrm{C}$ at $10^{\circ} \mathrm{C} / \mathrm{min}$ and held at an isotherm for $3 \mathrm{~min}$. The TGA data were plotted as temperature or heating rates versus \% weight loss or the derivative of $\%$ weight loss, from which onset and final decomposition temperatures were obtained. TGA was also used to determine the degradation kinetics of neat PLA, PCL, or composites. Each sample was heated at four different heating rates: $10,20,30$, and $40^{\circ} \mathrm{C} / \mathrm{min}$ under nitrogen. After analysis, kinetics data was obtained using the TA Specialty Library software, with reported activation energies at $50 \%$ conversion. The four heating rates were used to calculate the activation energy of degradation $(E a)$ using the equation known as Flynn and Walls [24].

\section{Results and Discussion}

3.1. Extrusion Compounding. Specific mechanical energy (SME) is a measure of how much mechanical energy went into a composite system during extrusion. Along with the thermal energy, SME can influence the melting and interaction between the components of the composite. In addition, the mechanical or thermal properties of the composite are dependent on SME, especially after cooling the product to room temperature. The glass transition of date pit powder was measured around $43^{\circ} \mathrm{C}$, and its degradation temperature $\left(T_{m}\right)$ was $197^{\circ} \mathrm{C}$ but decreased with increasing moisture content. The degradation onset of date pits could be as low as $110^{\circ} \mathrm{C}$ [4] depending on heating rate and moisture content. 


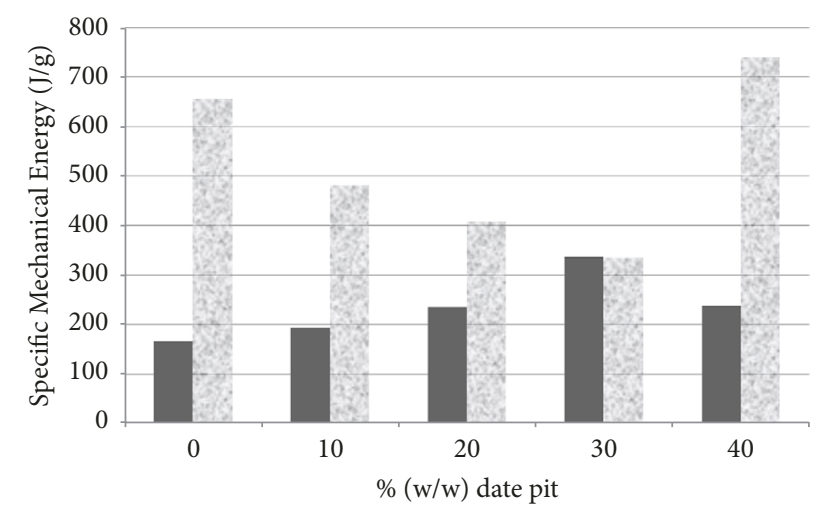

- PCL

PLA

FIGURE 1: Specific mechanical energy during extrusion processing of PCL and PLA composite blends with date pits.

Polymer-date pits composites were extruded above the melting temperature of PCL $\left(60^{\circ} \mathrm{C}\right)$ and at the melting temperature of PLA $\left(180^{\circ} \mathrm{C}\right)$. The SME of PCL-date pits composites increased as the amount of filler increased up to $30 \% \mathrm{w} / \mathrm{w}$ (Figure 1). This is a typical behavior when adding "hard" filler (DP) to "soft" material (i.e., low melting temperature) such as PCL. The extrusion temperature was not high enough to degrade (melt) the date pit filler. The reduction in SME at $40 \%$ DP filler can be attributed to the lubricating effect of water and/or oil found naturally in the $\mathrm{DP}$ as they approach a critical concentration relative to PCL content. PLA composites exhibited lower SME at 10, 20, and $30 \%$ DP filler (Figure 1). In this case, the polymer (PLA) is "harder" than the filler (DP); therefore the product was softer. The extrusion temperature necessary to melt PLA also tempered (soften) DP and further reduced SME. Nonetheless, at $40 \%$ filler the SME of PLA composite increased substantially (Figure 1). This increase can be attributed to the water evaporation due to the high extrusion temperature (was well above $100^{\circ} \mathrm{C}$ ) causing increase in the amount of energy needed to melt, mix, and convey the material through the extruder. In some circumstances, high SME can also indicate interaction between the components of the composite, either chemical or physical, such as crosslinking. The magnitude of SME is also a measure of the physicochemical state of melted polymer during extrusion. These results will be further discussed during the thermal analysis of the composites.

In earlier work, gluten was shown to interact with PLA during extrusion [23]. For the $40 \%$ blend with gluten (VG), the SME of PLA dropped from 660 to $338(\mathrm{~J} / \mathrm{g})$ and SME of PCL increased from 180 to $242(\mathrm{~J} / \mathrm{g})$. This drop can be attributed to lower PLA viscosity of the PLA composite and due to the plasticizing effect of gluten under the extrusion conditions and the opposite occurred for PCL. The dissimilar behavior of the PLA and PCL is due to the harder PLA compared to PCL. However, when comparing the SME of pure PLA and PCL polymers to the SME of the $40 \%$ DP composite, the SME of PLA increased from 660 to $740(\mathrm{~J} / \mathrm{g})$ whereas PCL exhibited increase from 180 to $240(\mathrm{~J} / \mathrm{g})$. The

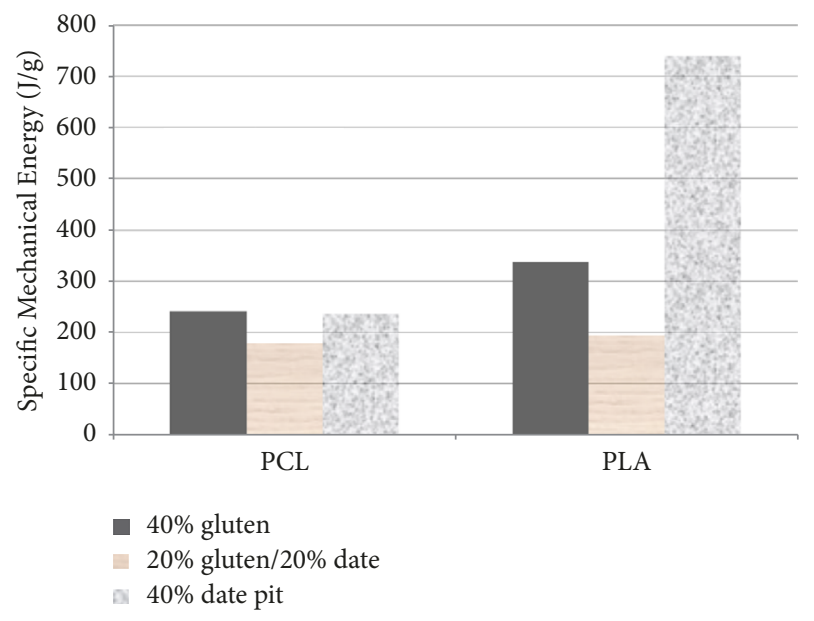

FIgURE 2: Specific mechanical energy during extrusion for PCL and PLA composites with gluten and date pits.

increase in SME at 40\% DP is due to the low plasticizing effect of DP compared to gluten. This could be attributed to the different behavior of gluten and DP during extrusion due to compositional differences [31-34]. Therefore, both polymers behaved differently at $40 \%$ DP where PLA exhibited higher SME not following the trend of the 10 to $30 \%$ DP and PCL showed lower SME contrary to the 10 to $30 \% \mathrm{DP}$.

When half of the gluten is replaced with date pit filler $(20 \% \mathrm{DP}+20 \% \mathrm{VG}+60 \%$ PLA or PCL $)$, the SME for PLA composites (the $40 \% \mathrm{DP}$ ) decreased significantly from $338 \mathrm{~J} / \mathrm{g}$ to 190 (Figure 2). On the other hand, when comparing the $40 \%$ DP composite to the $20 \%$ DP/20\% VG/60\% PLA, the SME of PLA dropped from $740 \mathrm{~J} / \mathrm{g}$ to $194 \mathrm{~J} / \mathrm{g}$ (Figure 2). This drop signifies synergy between VG and DP because individually they have tendency to increase SME at $40 \%$ concentration. Therefore, for extrusion efficiency both gluten and DP are recommended. For PCL plus 20\% VG and 20\% DP, SME decreased slightly from 242 to 190 when compared to the $40 \% \mathrm{VG}$ and decreased from 238 to $179 \mathrm{~J} / \mathrm{g}$ when compared with the $40 \%$ DP (Figure 2). This data reiterates the synergetic effect of VG and DP on the extrusion process. These values were similar to the processing values obtained for PCL composite containing 65\% gluten when adjusted for slower screw speeds and feed rate [22].

\section{Deferential Scanning Calorimetry (DSC)}

Samples PLA or PCL were subjected to DSC heating and cooling cycles. The DSC analysis of pure PLA revealed a glass transition followed by hot crystallization and immediate melting. These three events during the heating cycle continue to appear on the pure PLA profile as well as in the composites and were used as guide to determine the thermal properties of the composites.

Underneath of the glass transition of PLA profile, the enthalpic relaxation (ER) between $66^{\circ} \mathrm{C}$ and $68^{\circ} \mathrm{C}$ appeared which is a measure of PLA aging process. $\Delta H$ of ER at 0,10 , 20,30 , and $40 \%$ DP content of the composite were $4.81,4.55$, 


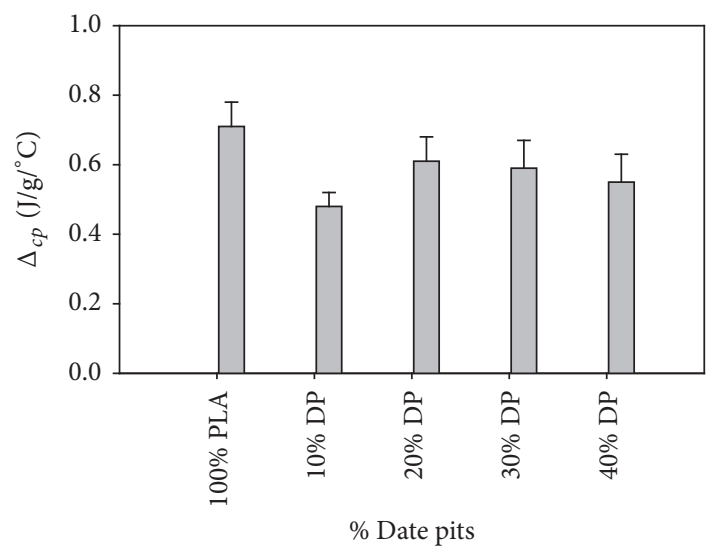

FIgURE 3: Effect of date pits on $\Delta H$ of PLA glass transition.

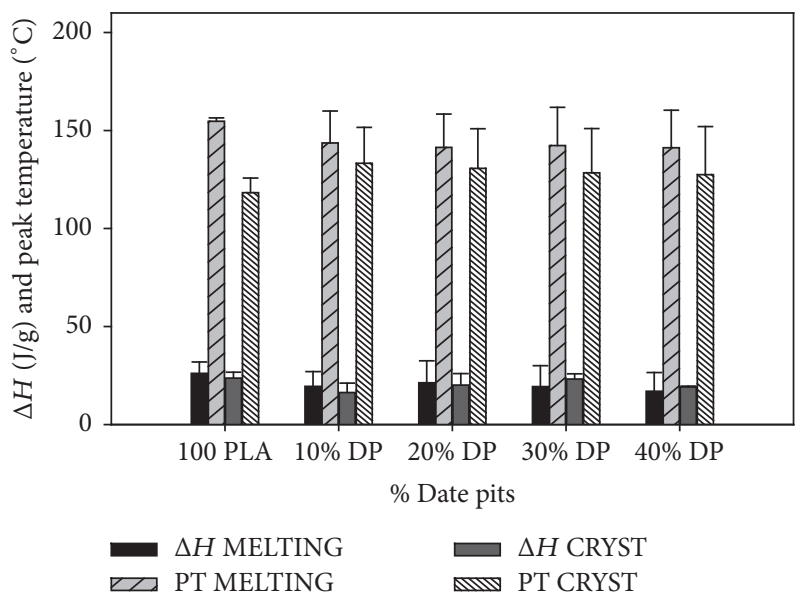

FIGURE 4: Effect of date pits on $\Delta H$ and peak temperature of melting and crystallization of PLA.

$3.96,2.95$, and $2.61 \mathrm{~J} / \mathrm{g}$, respectively. In general, the reason for the drop in ER appeared to be the absence PLA in the composite since this is a replacement study as shown in the composite formulation table (Table 1), because the ER is a characteristic of PLA.

The $T_{g}$ peak temperature of PLA has decreased at higher DP levels from $63^{\circ} \mathrm{C}$ to $57.9^{\circ} \mathrm{C}$ and the $\Delta_{C P}$ decreased as a function of higher DP level as illustrated in Figure 3. The peak temperature of PLA melting and crystallization dropped at $10 \%$ DP; however, the drop was negligible at higher DP. The range of decrease in $\Delta H$ of PLA melting and crystallization was between 16.9 and $26.1 \mathrm{~J} / \mathrm{g}$ for melting and 14.7 and $23.7 \mathrm{~J} / \mathrm{g}$ for crystallization (Figure 4). The drop in $\Delta H$ could be attributed, partially, to the reduction in PLA content (higher DP), but not entirely, because if the replacement was the only cause of the drop, the 10\% DP sample should have exhibited $23.4 \mathrm{~J} / \mathrm{g}$, but it was $19.5 \mathrm{~J} / \mathrm{g}$ (Figure 4). That signifies some sort of interaction (entanglement) between DP and PLA. During the cooling cycle, PLA exhibited one glass transition between 2 to $4^{\circ} \mathrm{C}$ earlier when compared to the glass transition during the heating cycle; that is, there was no PLA crystallization event during cooling.

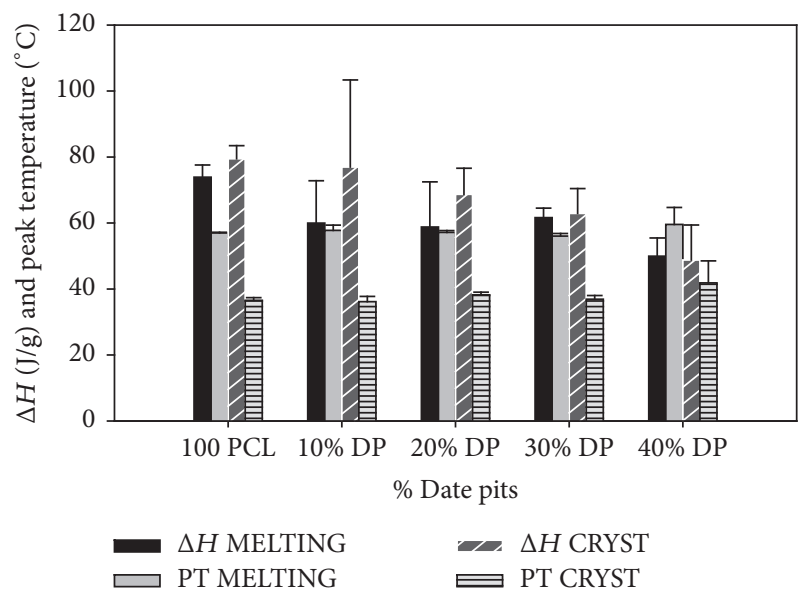

FIGURE 5: Effect of date pits on the $\Delta H$ and peak temperature of melting and crystallization of PCL.

PCL exhibited $\mathrm{Tg}$ at $-62.6^{\circ} \mathrm{C}$, melted at $56.8^{\circ} \mathrm{C}$, and crystallized during the cooling cycle at $36.6^{\circ} \mathrm{C}$. Tg of PCL was not affected by the DP which is in line with previous work [22] because at below zero temperature the molecular mobility of DP is very low which limits chances for interaction. During PCL melting, higher peak temperature was observed, whereas $\Delta H$ was significantly $(p<0.05)$ lower (drop from 77.9 to $47.1 \mathrm{~J} / \mathrm{g}$ ) as a function of DP indicating less stable PCL in the composite (Figure 5). Although the increase in peak temperature was not significant, but the significant drop in $\Delta H$ signifies quick disentanglement of the composite once the melting started, and that reduces the need for higher energy input (lower $\Delta H$ ). The crystallization profile during cooling showed significant drop on $\Delta H$ and significant increase in peak temperature (Figure 5). Unlike DP, the effect of vital gluten on the DSC analysis was not as obvious as it was on the SME discussed above. Representative DSC thermogram of one blend containing 70\% PLA and 30\% date pits is also presented in Figure 6(a) (thermal history) and Figure 6(b) (heating-cooling).

\section{Thermogravimetric Analysis}

Pure PLA or PCL exhibited one degradation peak at $353.5^{\circ} \mathrm{C}$ and $393.1^{\circ} \mathrm{C}$, respectively, as demonstrated by the TGA derivative plots (Figure 7). At $797^{\circ} \mathrm{C}$ and $800^{\circ} \mathrm{C}$, pure PLA and PCL degradation was completed. Both PLA and PCL polymers exhibited higher thermal stability than date pit (DP) or vital gluten (VG) because the degradation of DP started at $286^{\circ} \mathrm{C}$ and degraded completely at $799^{\circ} \mathrm{C}$ while VG started at 305 and completely degraded at $788^{\circ} \mathrm{C}$. Individually, DP and VG showed a small degradation peak at 59 and $60^{\circ} \mathrm{C}$, respectively, which appeared to be a moisture-loss peak. The TGA profile of the composites exhibited two distinct peaks, where the first peak represents the DP or VG and the second peak represents PLA or PCL. In Figure 6, the increase in the size of the first degradation peak around $300^{\circ} \mathrm{C}$ reflects the increase in DP whereas the second peak decreased at higher DP. Despite the difference in degradation profile of 


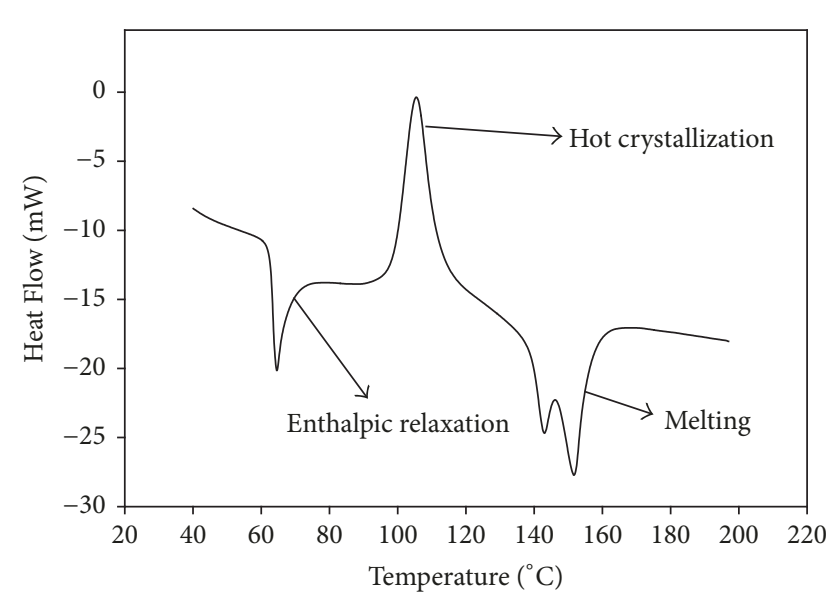

(a) Thermal history of PLA-date pits (70/30) blend

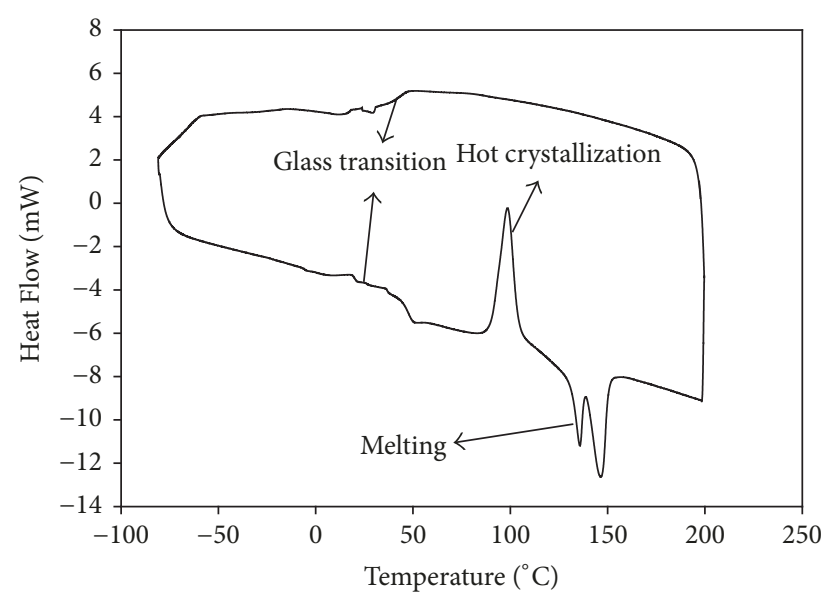

(b) DSC heating-cooling thermogram of PLA-date pits (70/30) blend

Figure 6

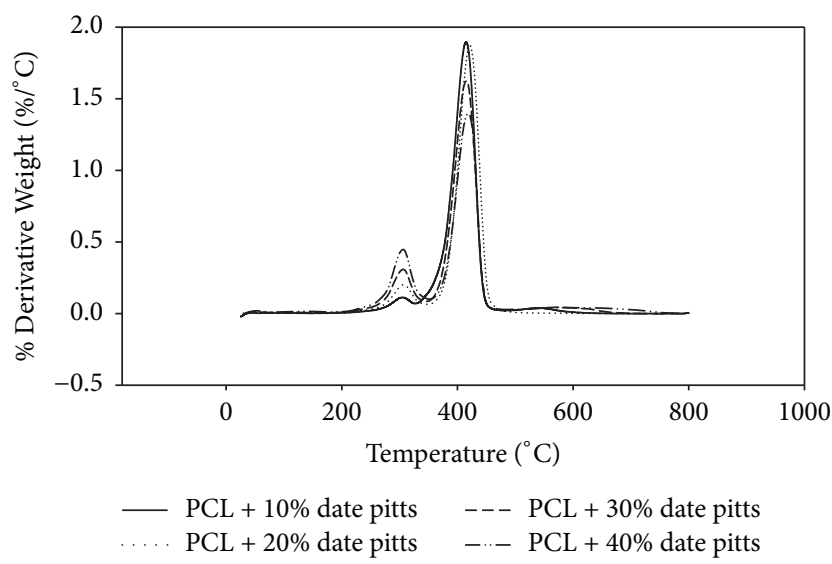

Figure 7: Derivative weight loss of PCL and date pits blends as a function of degradation temperature at $30^{\circ} \mathrm{C}$ heating rate.

pure PCL and DP, the profile of the composite showed no clear distinction between the copolymers, but the composite exhibited gradual drop on weight versus sharp drop of pure PCL. The gradual drop on weight loss curve indicates the presence of a third component produced during extrusion compounding. This third component appeared to have different physical properties compared to the PCL or DP. This data is in line with the DSC data, where a shift on the peak temperature and $\triangle H$ of PCL and PLA in the composite was confirmed. The remaining residue after degradation, mainly ash, was relative to the amount of DP because ash mostly comes from DP and VG. DP, PCL, PLA, and VG produced $3.36,0.20,0.80$, and $23.2 \%$ residue (ash), respectively. The presence of VG had little effect on PCL peak degradation temperature whereas PLA exhibited significant decrease in peak degradation temperature by $79^{\circ} \mathrm{C}$. This indicates some sort of physical interaction between VG and PLA since both are known to have hydrophobic surface property. This agrees with the data discussed above.

\section{Degradation Kinetics}

The difference in thermal degradation kinetics between the pure polymer and composites can be determined by degrading samples at different heating rates. As shown in Figure 8, higher heating rates resulted in higher weight loss, but composites with higher DP content exhibited lower percent weight loss compared to the pure polymer. This phenomenon was more obvious in the example of PLA composites compared to PCL. Hatakeyema et al. (2005) concluded that the addition of inorganic filler to polyurethane increased the decomposition temperature of the composite. The effect of DP appeared to be similar to inorganic fillers [35]. Figure 9 showed that PLA is more resistant to weight loss compared to PCL because it losses less weight than PCL for any heating rate value illustrated in Figure 8. Unlike PLA composites, VG did not show substantial effect on percent weight loss of PCL (Figure 10). These results are corroborated by the degradation temperature of PLA and PCL discussed earlier.

The mechanism of polymers degradation is known to depend on the heating rates which allow the determination of the degradation kinetics. In Figures 7 and 8, weight loss increased as a function of heating rate. Unlike PLA, pure PCL exhibited similar weight loss as the composite (data is not shown). The DP content had little effect the weight loss of PCL indicating lack of physical interface. The different degradation behavior of pure PCL and PLA is more obvious in Figure 8, where, for the same heating rate, PCL losses much more weight than PLA, but both polymers showed less weight loss at 20 and $30^{\circ} \mathrm{C} / \mathrm{min}$ compared to the 10 and $40^{\circ} \mathrm{C} / \mathrm{min}$ (Figure 8). The effect of $\mathrm{VG}$ on the degradation profile of PCL and PLA composite showed how PCL contact with VG was minimal, while PLA weight loss dropped as a function of VG content indicating some sort of interface interaction (Figure 9). Unlike PCL, higher VG content is shown to reduce the percent weight loss of PLA as function of heating rate.

The degradation kinetics of both composites was determined using TGA at 50\% degradation conversion. The activation energy of degradation $(E a)$ of the pure polymers 


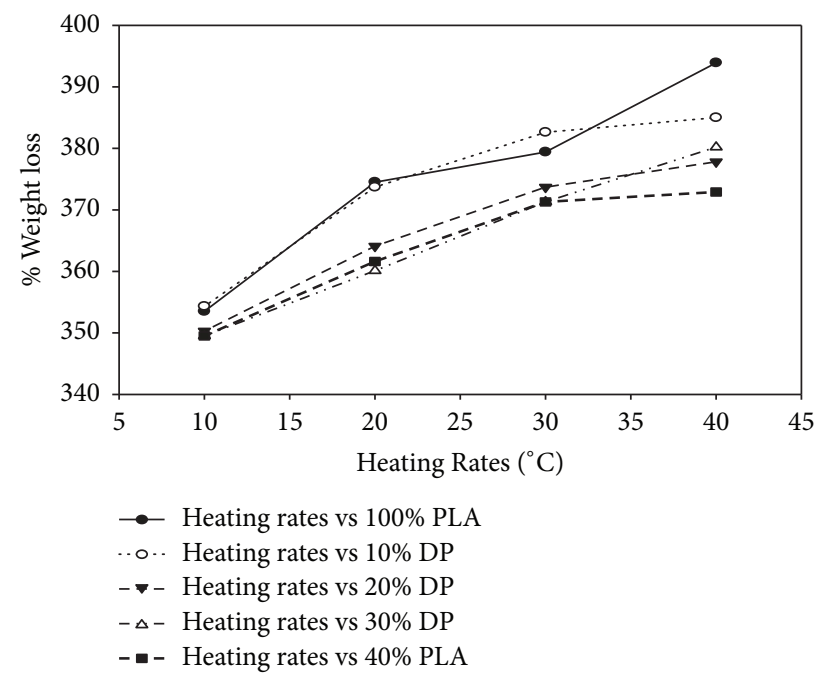

Figure 8: Derivative \% weight loss of PLA/dates pits at different heating rates.

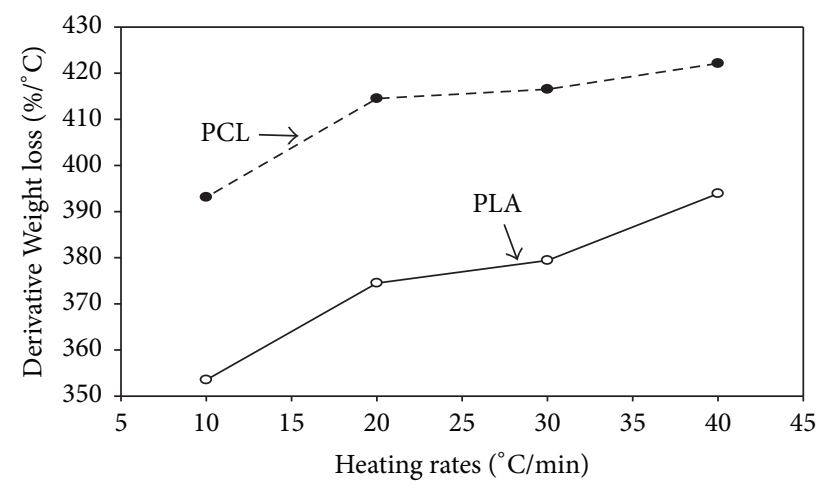

FIGURE 9: Degradation of PCL and PLA at different heating rates.

and the composites was obtained using Flynn and Walls equation [24] as follows:

$$
\begin{aligned}
\log \beta= & 0.457\left(-\frac{E a}{R T}\right) \\
& +\left[\log \left(\frac{A E a}{R}\right)-\log F(a)-2.315\right],
\end{aligned}
$$

where $\beta$ is the heating rate, $T$ is the absolute temperature, $R$ is the gas constant, $(a)$ is the percent conversion, $E a$ is the activation energy, and $A$ is the preexponential factor. According to this equation, at the same level of conversion, $E a$ can be obtained from the slope of the plot of $\log \beta$ as a function of 1000/T (k) for each heating rate and the percent conversion per minute is measured. The following equations ((3)-(5)) are the basis for the most published methods used for calculating the kinetics parameters from TGA data:

$$
R=\frac{d a}{d t}=k(T) f(a)
$$

where $f(a)$ is the reaction model, $(a)$ is the extend of the reaction, $k(T)$ is the temperature-dependent rate where $k$ is

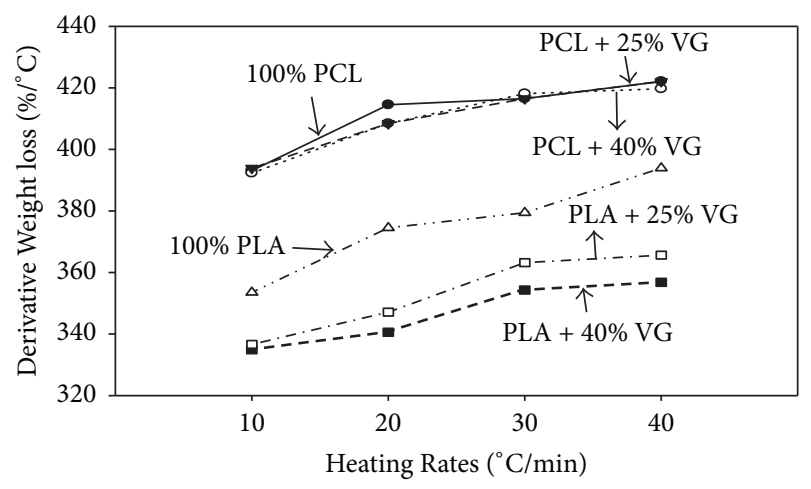

FIgURE 10: \% loss of PCL and PLA vital gluten blends at different heating rates.

the constant, $T$ is the temperature, " $t$ " is the time, and $R$ is the rate of degradation. The term $k(T)$ is assumed to obey the Arrhenius law as follows:

$$
k(T)=A e p\left(\frac{-E}{R T}\right),
$$

where $E$ is the activation energy, $A$ is the preexponential factor, and $R$ is the gas constant. Finally, the degradation is considered a simple $n$ th-order reaction as in the following expression of the conversion dependents is shown in the following:

$$
f(a)=(1-a)^{n}=W^{n},
$$

where $n$ is the reaction order and $W$ is the weight of the residual undegraded material. This method is used for either single or multiple heating rates. The TGA of degradation kinetics theory is based on the fact that the activation energy $(E a)$ is constant for certain level of conversion. The percent conversion versus time can be used to show the percent and temperature of conversion over time for three or more heating rates. As expected, higher heating rates result in faster conversion.

The profiles of all percent degradation conversion as a function of heating rates showed similar occurrences of linear lines with different slopes at each degradation conversion level (Figures 11(a) and 11(b)). The slopes of these lines represent the activation energy $(E a)$. The linear lines for each conversion showed that Ea exhibited measurablechange throughout the degradation process indicating the domination of one-step kinetic mechanism or pathway for the pure polymers and some of the composites. The degradation profile of neat PCL was measured between 5 and $20 \%$ conversion, whereas the composites data was determined between 10 and $70 \%$ conversion at $10 \%$ increment. Figures $11(\mathrm{a})$ and $11(\mathrm{~b})$ represent pure PCL and $60 \%$ PCL $+40 \%$ DP, respectively. Although all composites were tested for their degradation kinetics, Figure 11 is just a representative profile, where the remaining data of PCL and PLA was used directly for $E a$ calculation. The mechanism of degradation is considered a one-step process when all $E a$ points as a function of percent conversions fall on strait upward line 


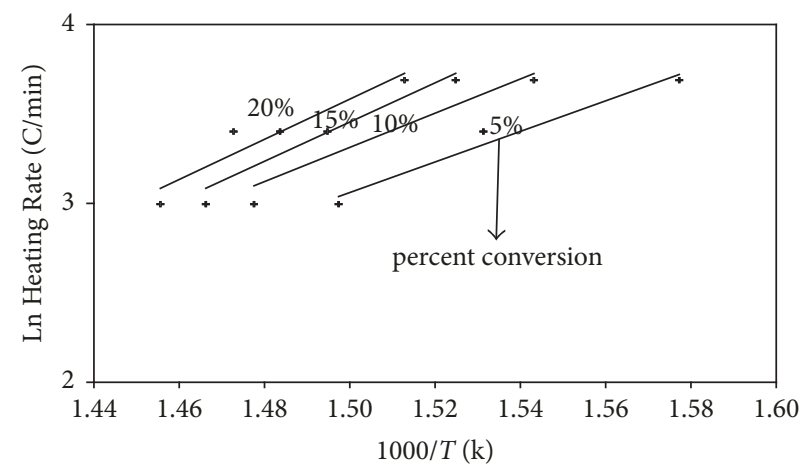

(a) PCL percent degradation conversion as a function of heating rate

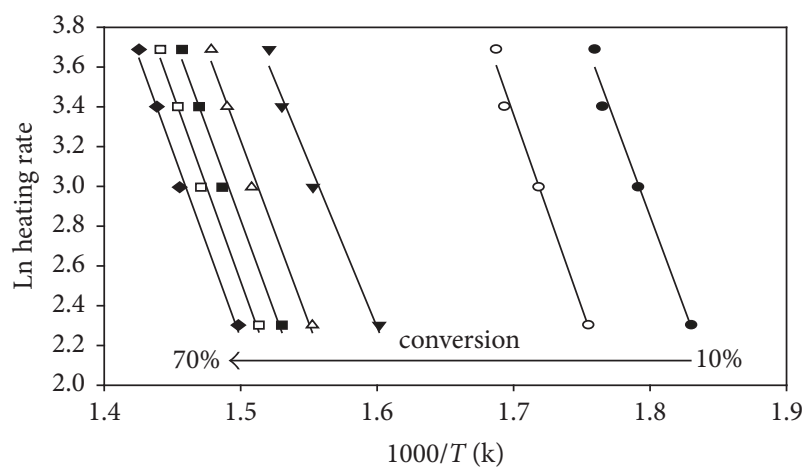

(b) $60 \%$ PCL $/ 40 \%$ date pits: percent conversion as a function of heating rates

Figure 11

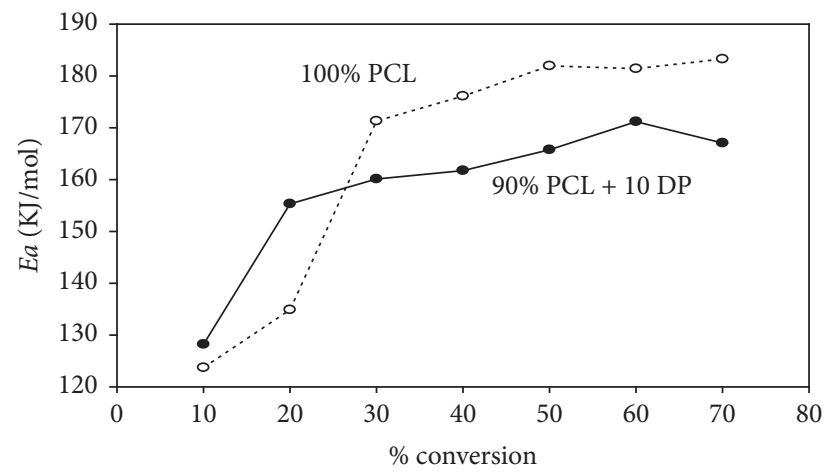

FIGURE 12: Activation energy as a function of percent conversion of $100 \%$ PCL and $90 \%$ PCL $+10 \%$ date pits (DP).

regardless of the number of heating rates points. In Figure 12, the multistep line indicates more than one-step degradation event of pure PCL, while the addition of $10 \%$ date pits (DP) turned into a one-step event which indicates some sort of physical influence of DP on PCL. In the same figure, lower $E a$ was observed due to the $10 \%$ DP; that is, the $10 \%$ DP did not change the number of degradation steps and it reduced $E a$ as well. Nonetheless, the picture is completely different for the PCL $+20 \%$ gluten $+20 \%$ DP composite where multistep degradation was detected indicating more engagement of PCL in the presence of VG (Figure 13). In addition, during the discussion of SME of PCL (Figure 2), VG had much less effect on PCL than DP. Besides the multistep degradation of PCL, higher $E a$ at higher percent conversion was also detected due to VG (Figure 13).

The degradation mechanism of pure PLA exhibited one step (Figure 14) regardless of percent conversion, but in the same figure it is quite clear the much higher $E a$ of PLA + $10 \%$ DP relative to the pure PLA. The degradation kinetics of PLA (Figure 14) showed how 10\% DP significantly increased $E a$ of pure PLA by about $35 \mathrm{KJ} / \mathrm{mol}$, but the mechanism stayed just about the same as one-step process matching the pure PLA. All PLA composites exhibited significant change in the degradation mechanism from a one-step to a multistep process (Figure 15). The change in degradation kinetics of

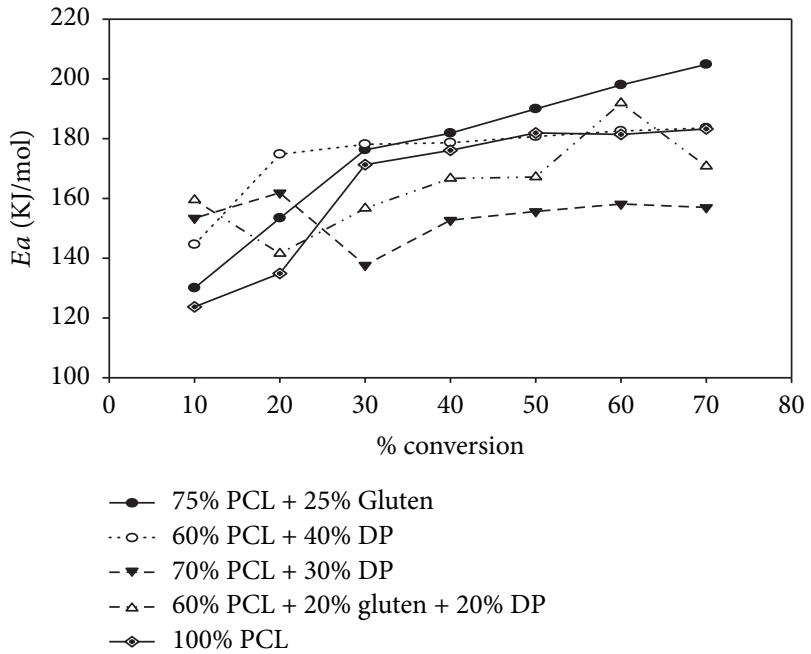

FIGURE 13: Degradation mechanism of different PCL composites.

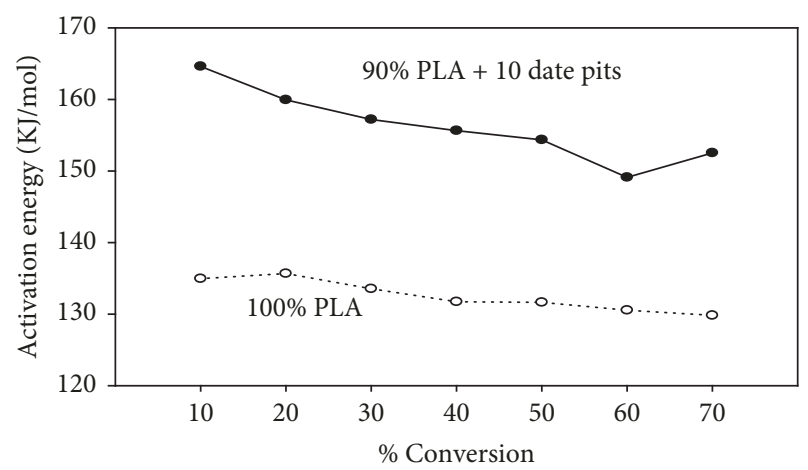

FIgURE 14: Neat PLA and 90\% PLA $+10 \%$ date pits: activation energy as a function of percent degradation conversion.

PLA intensified at higher DP and less in the presence of VG (Figure 15)

This data disclosed the big difference between the pure polymer and the composites with respect to the thermomechanical properties. Change in the degradation steps 


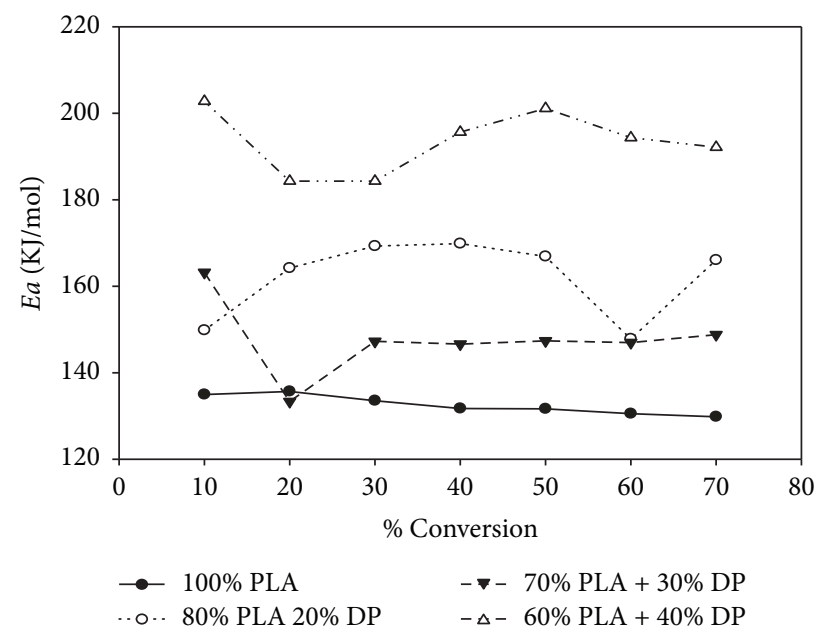

Figure 15: Degradation mechanism of different PLA blends.

could be ascribed to the creation of a third component during extrusion as mentioned earlier. The phenomenon of the creation of a third component in a two-component composite is well established in the literature but mostly in the synthetic polymers composites rather than biopolymers $[22,23]$. Nonetheless, the creation of a third component is evident in the degradation profile of PLA or PCL discussed above.

\section{Conclusions}

As shown by the specific mechanical energy (SME) results, the addition of date pits transformed the physical properties of PLA and PCL. The SME data was corroborated by thermal analysis as well. Thermal degradation data illustrated the significant effect of date pits on PLA or PCL thermal degradation kinetics. The thermal analysis revealed significant drop on $\Delta H$ as a function of DP. In addition, increase on the peak temperature as a function of DP was observed. There was a slight drop on $\Delta C_{p}$ of PLA in the composite, whereas the glass transition of the composite was increased. The TGA profiles of pure PCL and PLA exhibited one degradation peak, whereas composites profiles included two peaks, the first peak of the composite represents the DP or gluten and its size represents the DP content. DP appeared to mix with PLA better than PCL. The degradation mechanism of PCL and PLA was more influenced by DP compared with gluten. The data showed multistep degradation mechanism which is indicative of interaction or the formation of a third component in a two-component system. The data showed the importance of selecting the appropriate filler (hard versus soft) according to the desired composite.

\section{Conflicts of Interest}

The authors declared no potential conflicts of interest with respect to the research, authorship, and/or publication of this article.

\section{Acknowledgments}

The research team would like to express their gratitude and appreciation to King Abdulaziz City for Science and Technology (KACST) for providing the research grant for Project no. “A-T-3220.”

\section{References}

[1] H. A. Almana and R. M. Mahmoud, "Palm date seeds as an alternative source of dietary fiber in Saudi Bread," Ecology of Food and Nutrition, vol. 32, no. 3-4, pp. 261-270, 1994.

[2] E. A. Elgasim, Y. A. Alyousef, and A. M. Humeid, "Possible hormonal activity of date pits and flesh fed to meat animals," Food Chemistry, vol. 52, no. 2, pp. 149-152, 1995.

[3] J. S. Hamada, I. B. Hashim, and F. A. Sharif, "Preliminary analysis and potential uses of date pits in foods," Food Chemistry, vol. 76, no. 2, pp. 135-137, 2002.

[4] M. S. Rahman, S. Kasapis, N. S. Z. Al-Kharusi, I. M. Al-Marhubi, and A. J. Khan, "Composition characterisation and thermal transition of date pits powders," Journal of Food Engineering, vol. 80, no. 1, pp. 1-10, 2007.

[5] F. D. Alsewailem and Y. A. Binkhder, "Preparation and characterization of polymer/date pits composites," Journal of Reinforced Plastics and Composites, vol. 29, no. 11, pp. 1743-1749, 2010.

[6] M. C. Gupta and V. G. Deshmukh, “Thermal oxidative degradation of poly-lactic acid - Part I: Activation energy of thermal degradation in air," colloid and polymer science, vol. 260, no. 3, pp. 308-311, 1982.

[7] F. Signori, M.-B. Coltelli, and S. Bronco, "Thermal degradation of poly(lactic acid) (PLA) and poly(butylene adipate-coterephthalate) (PBAT) and their blends upon melt processing," Polymer Degradation and Stability, vol. 94, no. 1, pp. 74-82, 2009.

[8] T. Zaharescu, M. Râpă, and V. Marinescu, "Chemiluminescence kinetic analysis on the oxidative degradation of poly(lactic acid)," Journal of Thermal Analysis and Calorimetry, vol. 128, no. 1, pp. 185-191, 2017.

[9] S.-H. Hyon, K. Jamshidi, and Y. Ikada, "Effects of Residual Monomer on the Degradation of DL-Lactide Polymer," Polymer International, vol. 46, no. 3, pp. 196-202, 1998.

[10] S. Gogolewski, M. Jovanovic, S. M. Perren, J. G. Dillon, and M. K. Hughes, "The effect of melt-processing on the degradation of selected polyhydroxyacids: polylactides, polyhydroxybutyrate, and polyhydroxybutyrate-co-valerates," Polymer Degradation and Stability, vol. 40, no. 3, pp. 313-322, 1993.

[11] Y. Aoyagi, K. Yamashita, and Y. Doi, "Thermal degradation of poly[(R)-3-hydroxybutyrate], poly[ $\varepsilon$-caprolactone], and poly[(S)-lactide]," Polymer Degradation and Stability, vol. 76, no. 1, pp. 53-59, 2002.

[12] F.-D. Kopinke, M. Remmler, K. Mackenzie, M. Möder, and O. Wachsen, "Thermal decomposition of biodegradable polyesters-II. Poly(lactic acid)," Polymer Degradation and Stability, vol. 53, no. 3, pp. 329-342, 1996.

[13] H. Tsuji, Y. Echizen, and Y. Nishimura, "Photodegradation of biodegradable polyesters: A comprehensive study on poly(llactide) and poly(E-caprolactone)," Polymer Degradation and Stability, vol. 91, no. 5, pp. 1128-1137, 2006.

[14] O. Wachsen, K. Platkowski, and K.-H. Reichert, "Thermal degradation of poly-l -lactide -studies on kinetics, modelling 
and melt stabilisation," Polymer Degradation and Stability, vol. 57, no. 1, pp. 87-94, 1997.

[15] L. G. Griffith, "Polymeric biomaterials," Acta Materialia, vol. 48, no. 1, pp. 263-277, 2000.

[16] R. Chandra and R. Rustgi, "Biodegradable polymers," Progress in Polymer Science, vol. 23, no. 7, pp. 1273-1335, 1998.

[17] D. Darwis, H. Mitomo, T. Enjoji, F. Yoshii, and K. Makuuchi, "Enzymatic degradation of radiation crosslinked poly $(\varepsilon$ caprolactone)," Polymer Degradation and Stability, vol. 62, no. 2, pp. 259-265, 1998.

[18] L. Yu, K. Dean, and L. Li, "Polymer blends and composites from renewable resources," Progress in Polymer Science, vol. 31, no. 6, pp. 576-602, 2006.

[19] A. K. Bledzki and J. Gassan, "Composites reinforced with cellulose based fibres," Progress in Polymer Science, vol. 24, no. 2, pp. 221-274, 1999.

[20] A. K. Mohanty, M. Misra, and G. Hinrichsen, "Biofibres, biodegradable polymers and biocomposites: an overview," Macromolecular Materials and Engineering, vol. 276-277, pp. 124, 2000.

[21] S. Wong, R. Shanks, and A. Hodzic, "Properties of poly(3hydroxybutyric acid) composites with flax fibres modified by plasticiser absorption," Macromolecular Materials and Engineering, vol. 287, no. 10, pp. 647-655, 2002.

[22] A. Mohamed, V. L. Finkenstadt, S. H. Gordon, G. Biresaw, E. P. Debra, and P. Rayas-Duarte, "Thermal properties of PCL/gluten bioblends characterized by TGA, DSC, SEM, and infrared-PAS," Journal of Applied Polymer Science, vol. 110, no. 5, pp. 3256-3266, 2008.

[23] A. A. Mohamed, S. H. Gordon, C. J. Carriere, and S. Kim, "Thermal characteristics of polylactic acid/wheat gluten blends," Journal of Food Quality, vol. 29, no. 3, pp. 266-281, 2006.

[24] J. H. Flynn and L. A. Wall, "A quick direct method for the determination of activation energy from thermogravimetric data, Journal of Polymer Science Part C: Polymer Letters, pp. 323-330, 1966.

[25] N. Salahuddin and M. Shehata, "Polymethylmethacrylatemontmorillonite composites: Preparation, characterization and properties," Polymer Journal, vol. 42, no. 20, pp. 8379-8385, 2001.

[26] A. Ashori and A. Nourbakhsh, "Effects of nanoclay as a reinforcement filler on the physical and mechanical properties of wood-based composite," Journal of Composite Materials, vol. 43, no. 18, pp. 1869-1875, 2009.

[27] M. Urzúa, L. Gargallo, and D. Radic, "Blends Containing Amphiphilic Polymers. II. Poly(N-1-Alkyl Itaconamic Acids) with Poly(4-Vinylpyridine) and Poly(2-Hydroxypropyl Methacrylate)," Journal of Macromolecular Science, Part B Physics, vol. 39, no. 2, pp. 143-154, 2000.

[28] Y. J. Kim, T. Hagiwara, K. Kawai, T. Suzuki, and R. Takai, "Kinetic process of enthalpy relaxation of glassy starch and effect of physical aging upon its water vapor permeability property," Carbohydrate Polymers, vol. 53, no. 3, pp. 289-296, 2003.

[29] M. Gordon and J. S. Taylor, "Ideal copolymers and the secondorder transitions of synthetic rubbers. i. non-crystalline copolymers," Journal of Applied Chemistry, vol. 2, no. 9, pp. 493-500, 1952.

[30] F. Badii, W. MacNaughtan, and I. A. Farhat, "Enthalpy relaxation of gelatin in the glassy state," International Journal of Biological Macromolecules, vol. 36, no. 4, pp. 263-269, 2005.
[31] O. Myllymäki, T. Eerikäinen, T. Suortti, P. Forssell, P. Linko, and K. Poutanen, "Depolymerization of barley starch during extrusion in water glycerol mixtures," LWT-Food Science and Technology, vol. 30, no. 4, pp. 351-358, 1997.

[32] S. Godavarti and M. V. Karwe, "Determination of specific mechanical energy distribution on a twin-screw extruder," Journal of Agricultural and Engineering Research, vol. 67, no. 4, pp. 277-287, 1997.

[33] N. D. Frame, The Technology of Extrusion Cooking, N. D. Frame, Ed., Blakie Academic \& Professional, Glasgow, 1994.

[34] C. Mercier, P. Linko, and M. J. Harper, Eds., Extrusion Cooking. Minnesota: American Association of Cereal Chemists, 1989.

[35] H. Hatakeyema, N. Tanamachi, H. Matsumura, S. Hirose, and T. Hatakeyama, "Bio-based polyurethane composite foams with inorganic fillers studied by thermogravimetry," Thermochimica Acta, vol. 431, no. 1-2, pp. 155-160, 2005. 


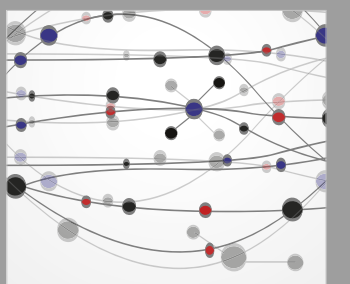

The Scientific World Journal
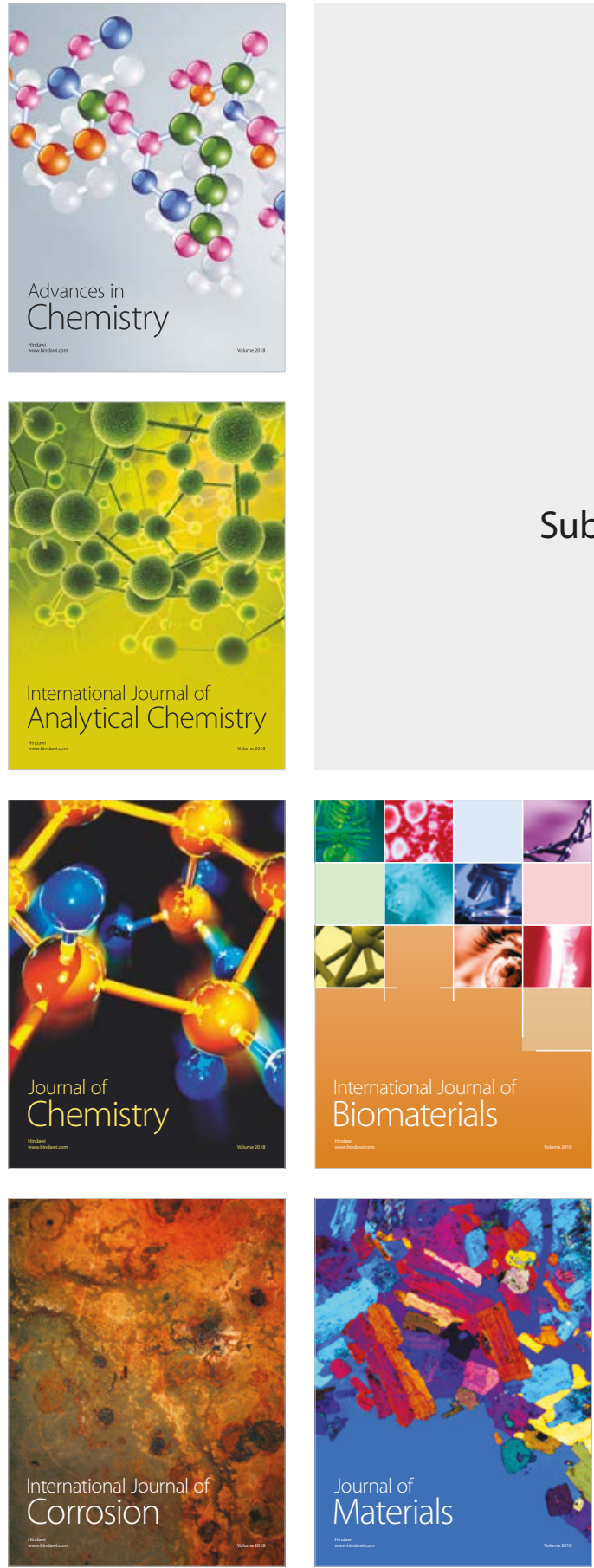

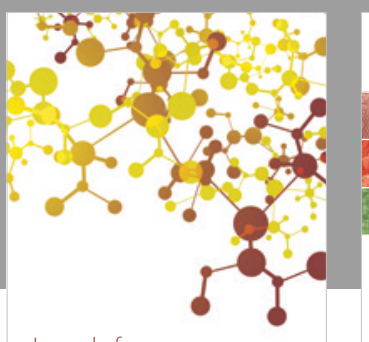

Journal of

Applied Chemistry
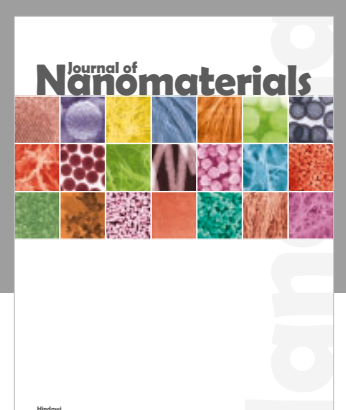

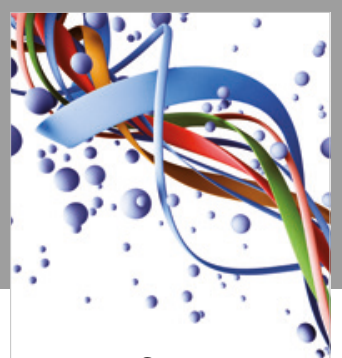

Scientifica

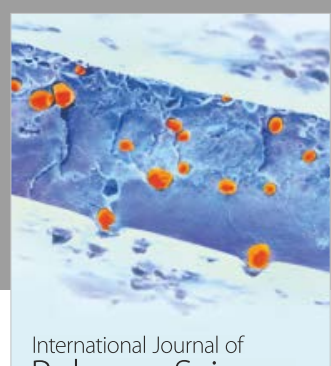

Polymer Science

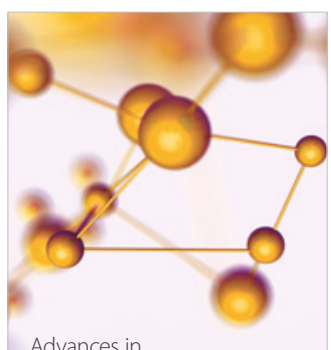

Physical Chemistry
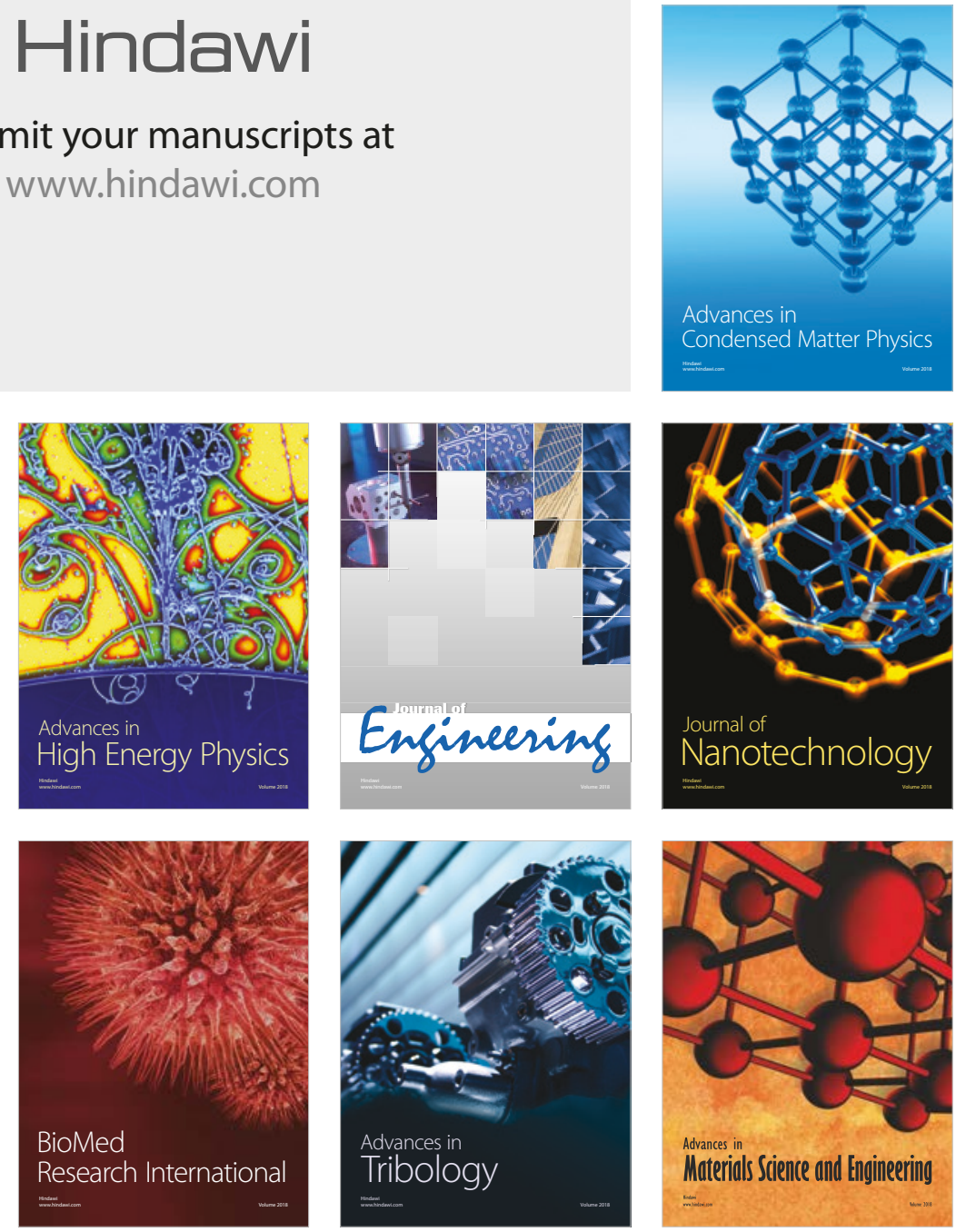